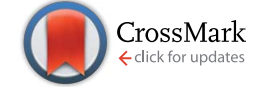

Cite this: RSC Adv., 2016, 6, 114658

\title{
Atomic layer deposition of vanadium oxides for thin-film lithium-ion battery applications $\uparrow$
}

\author{
Felix Mattelaer, ${ }^{*}$ Kobe Geryl, Geert Rampelberg, Thomas Dobbelaere, \\ Jolien Dendooven and Christophe Detavernier
}

\begin{abstract}
Amorphous $\mathrm{VO}_{2}$ thin films are deposited by atomic layer deposition (ALD) using tetrakis[ethylmethylamino] vanadium (TEMAV) as vanadium precursor and water or ozone as the oxygen source. The crystallisation and oxidation behaviour is investigated for different oxygen partial pressures between ambient air and 3.7 Pa, resulting in phase formation diagrams on $\mathrm{SiO}_{2}, \mathrm{TiN}$ and $\mathrm{Pt}$ substrates, demonstrating a series of stable vanadium oxide phases in the $\mathrm{VO}_{2}-\mathrm{V}_{2} \mathrm{O}_{5}$ series. Most of the obtained phases exhibit lithium intercalation behaviour in the 1.5-4.5 V vs. $\mathrm{Li}^{+} / \mathrm{Li}$ potential range, and demonstrate high volumetric capacities in the order of $\mathrm{V}_{2} \mathrm{O}_{5}<\mathrm{VO}_{2}(\mathrm{~B})<\mathrm{V}_{6} \mathrm{O}_{13}<\mathrm{V}_{3} \mathrm{O}_{7}<\mathrm{V}_{4} \mathrm{O}_{9}$, with the latter at more than twice the capacity of the best commercial cathode materials.
\end{abstract}

Received 24th October 2016 Accepted 30th November 2016

DOI: 10.1039/c6ra25742a

www.rsc.org/advances

\section{Introduction}

The development of an 'internet of things' requires both wireless sensor networks and autonomous microsystems. ${ }^{\mathbf{1} 2}$ While the electronics, sensors and wireless communication systems abide Moore's law, the energy storage devices lag behind. ${ }^{2,3}$ To advance from traditional secondary batteries to energy storage systems tuned for these micro-devices, all-solid state thin-film batteries can provide the answer. ${ }^{4}$ While the removal of a liquid component in an all-solid state battery provides a huge advancement in battery safety and bio-compatibility, ${ }^{5}$ the thinfilm approach provides integrability to on-chip devices as well as improved charge-discharge kinetics.

Due to the transition-metal nature of vanadium oxides and the high number of vanadium-oxygen ratio compositions, vanadium oxides are heavily investigated materials for applications such as catalysis, ${ }^{6}$ optical switching ${ }^{7}$ and thin-film batteries. ${ }^{8-17}$ Although $\mathrm{V}_{2} \mathrm{O}_{5}$ and $\mathrm{VO}_{2}$ (B) are the most investigated cathode materials in lithium ion battery research, ${ }^{8-17}$ all vanadium oxides in the Wadsley series $\left(\mathrm{V}_{n} \mathrm{O}_{2 n+1}\right)$ are related to one another ${ }^{18}$ and show promising electrochemical properties. ${ }^{19,20}$ Even though vanadium oxides have a high theoretical energy density, they suffer from poor charge-discharge kinetics due to their moderate electronic conductivity and intrinsically low ionic diffusion. ${ }^{21}$

Upon going from a typical thin-film battery ( 1 to $10 \mu \mathrm{m}$ thick electrodes) to truly thin-film electrodes (10 to $100 \mathrm{~nm})$, the resistance for electronic current drops by orders of magnitude,

Department of Solid State Sciences, Ghent University, Krijgslaan 281 S1, 9000 Gent, Belgium. E-mail: felix.mattelaer@ugent.be

$\dagger$ Electronic supplementary information (ESI) available: In situ XRD during the formation of crystalline films for electrochemical testing, and cyclic voltammetry of the Pt substrate. See DOI: 10.1039/c6ra25742a and interface intercalation dominates over the bulk diffusion. ${ }^{22}$ However, the thin-film nature of these batteries inherently leads to a low energy density. This problem can be overcome by depositing these thin-films on complex battery architectures leading to significant enhancements in effective surface area and thus in energy density per footprint area. ${ }^{23-27}$ Many deposition techniques have been used to deposit a variety of vanadium oxides such as PVD, ${ }^{28,29}$ sol-gel ${ }^{29}$ and CVD, ${ }^{30}$ however, only few techniques have the high step-coverage of atomic layer deposition (ALD) required to coat the high-aspect-ratio structures required in 3D thin-film batteries. ${ }^{31}$ Several ALD processes exist for vanadium oxides. ${ }^{7,32-38}$

In this work, we will investigate the formation of vanadium oxide thin films in the $\mathrm{VO}_{2}-\mathrm{V}_{2} \mathrm{O}_{5}$ series, based on the atomic layer deposition of amorphous $\mathrm{VO}_{2}$. We will show that we can obtain all vanadium oxide phases in the series by changing the post-deposition annealing conditions, and demonstrate electrochemical activity of different phases.

\section{Experimental}

The vanadium oxides were grown in an experimental highvacuum ALD setup with a base pressure of $10^{-7}$ mbar with walls heated at $95{ }^{\circ} \mathrm{C}^{31,38,39}$ The ALD process used here was characterised earlier by Rampelberg et al. ${ }^{7,34-36,40}$ and is based on tetrakis[ethylmethylamino]vanadium $\left(\mathrm{V}\left(\mathrm{NC}_{2} \mathrm{H}_{5} \mathrm{CH}_{3}\right)_{4}\right.$, or TEMAV) in combination with $\mathrm{H}_{2} \mathrm{O}$ and ozone. The precursor was held in a stainless steel container at $70{ }^{\circ} \mathrm{C}$ with argon as a carrier gas. TEMAV and argon were pulsed at a pressure of $6 \times$ $10^{-3}$ mbar. As reactant gases $\mathrm{H}_{2} \mathrm{O}$ and $\mathrm{O}_{3}$ were applied, pulsed at $7.5 \times 10^{-3} \mathrm{mbar}$ and $2 \times 10^{-1} \mathrm{mbar}$, respectively. The ozone was produced with an OzoneLab ${ }^{\mathrm{TM}}$ generator from a pure $\mathrm{O}_{2}$ gas flow, resulting in a minimal concentration of $150 \mu \mathrm{g} \mathrm{ml} \mathrm{m}^{-1}$. In 
between pulses, reaction products and remaining precursor or reactant gas were evacuated using a turbomolecular pump to a pressure of $<2.0 \times 10^{-6} \mathrm{mbar}$. The films were grown on silicon substrates covered with $100 \mathrm{~nm}$ thermal $\mathrm{SiO}_{2}$, $60 \mathrm{~nm}$ PVD TiN and $80 \mathrm{~nm}$ PVD Pt. Two thermal ALD processes were used here: the TEMAV $-\mathrm{H}_{2} \mathrm{O}$ process and the TEMAV- $\mathrm{O}_{3}$ process. To ensure similar conditions, both processes were performed at a substrate temperature of $150{ }^{\circ} \mathrm{C}$ with saturated process parameters, as determined by earlier experiments. ${ }^{7,36}$ Pulse times for the TEMAV precursor were 5 and $4 \mathrm{~s}$ in the water and ozone processes. Water and ozone pulse times were $5 \mathrm{~s}$ on the $\mathrm{SiO}_{2}$ substrate. The Pt substrate influenced the growth, as was also reported by Premkumar et al., ${ }^{34}$ so higher ozone pulse times $(8 \mathrm{~s})$ were required to ensure uniform films. The growth rate for the water process was $0.67 \AA$ per cycle. The growth rate for the ozone process was $1.05 \AA$ per cycle, a higher value than reported by Rampelberg et al., ${ }^{7}$ but still lower than the reported value by Premkumar et al. $^{34}$

$\mathrm{X}$-Ray techniques were used to determine film thickness (Xray reflectivity or XRR), crystallinity (X-ray diffraction or XRD) and film composition and oxidation state (X-ray photoelectron spectroscopy or XPS). XRR and XRD were performed in a Bruker D8 Discover using a copper $\mathrm{X}$-ray source $(\mathrm{Cu}-\mathrm{K} \alpha$ radiation at $0.154 \mathrm{~nm}$ ) and a point detector (for XRR) or a linear detector (for XRD). To determine the film crystallinity during annealing in a controlled ambient, in situ XRD was performed using a linear detector and a controlled ambient/temperature system. XPS was performed using $\mathrm{Al}-\mathrm{K} \alpha$ radiation $(0.834 \mathrm{~nm})$ under a take-off angle of $45^{\circ}$ in a high-vacuum chamber $\left(2 \times 10^{-9}\right.$ mbar $)$. A resolution of $0.108 \mathrm{eV}$ was obtained.

The film morphology was probed using a Bruker Dimension Edge atomic force microscope (AFM) and film rms roughnesses were determined from $1 \mu \mathrm{m} \times 1 \mu \mathrm{m}$ AFM images.

Electrochemical measurements were performed in an Arfilled glove box $\left(\mathrm{O}_{2}<1 \mathrm{ppm}, \mathrm{H}_{2} \mathrm{O}<1 \mathrm{ppm}\right)$ with a Metrohm Autolab PGSTAT302 connected to a three-electrode setup. Electrical contact to the TiN or Pt current collector was made by contacting the side of the sample with silver paste to a $\mathrm{Cu}$ foil. Lithium ribbon (99.9\%, Sigma Aldrich) was used as counter and reference electrodes, and $1 \mathrm{M} \mathrm{LiClO}_{4}$ in propylene carbonate (99\%, io-li-tec) was used as $\mathrm{Li}^{+}$electrolyte solution. Cyclic voltammetry $(\mathrm{CV})$ measurements were performed at a $10 \mathrm{mV} \mathrm{s}^{-1}$ sweep rate between 1.5 and $4.5 \mathrm{~V} v s$. $\mathrm{Li}^{+} / \mathrm{Li}$, or relevant potential boundaries. Galvanostatic charge-discharge measurements were performed to examine the capacity and thin film kinetics at varying current densities.

\section{Results and discussion}

\section{1 $\mathrm{VO}_{x}$ thin film deposition by thermal ALD}

First, the properties of the as-deposited amorphous films were investigated. The rms roughness of the as-deposited films on a Pt substrate, as measured by AFM, was 1.95 and $1.77 \mathrm{~nm}$ for the $\mathrm{H}_{2} \mathrm{O}$ - and $\mathrm{O}_{3}$-based films, respectively. The Pt substrate was also measured, and showed a roughness of $1.75 \mathrm{~nm}$, so the deposition of a $10 \mathrm{~nm}$ film on the substrate barely increases the roughness, indicating smooth films. The surface morphology was investigated using SEM, and images are shown in Fig. 1 for both films on the $\mathrm{Pt}$ substrate. A very similar granular morphology is observed for both processes. These results imply that the choice of process barely influences the as-deposited film morphology and topology.

Next, the film composition was investigated using XPS. Since vanadium oxides are reported to be very sensitive to the preferential sputtering of oxygen during depth profiling with XPS, only the surface spectra are evaluated to determine the composition and the oxidation state. ${ }^{42}$ The measured spectra were calibrated to the $\mathrm{O} 1 \mathrm{~s}$ signals at $530.0 \mathrm{eV}$, since calibrating using the $\mathrm{C} 1 \mathrm{~s}$ peak is not ideal for vanadium oxides. ${ }^{41}$ As the $\mathrm{V}$ 2p core level binding energy depends strongly on its oxidation state, ${ }^{7,42}$ fitting can be used to determine the oxidation state of the as-deposited films. Furthermore, the separation of the $\mathrm{V} 2 \mathrm{p}_{3 / 2}$ peak from the $\mathrm{O} 1 \mathrm{~s} \mathrm{VO}_{x}$-component at $530.0 \mathrm{eV}$ was also used to compare the two as-deposited ALD films. ${ }^{42}$ Fig. 2 shows the results of this analysis, alongside $\mathrm{a}_{2} \mathrm{O}_{5}$ reference, using the reported binding energies for the V2p components: 515.8 and $523.2 \mathrm{eV}$ for the $\mathrm{V} 2 \mathrm{p}_{3 / 2}$ and $\mathrm{V} 2 \mathrm{p}_{1 / 2}$, and 517.2 and $524.5 \mathrm{eV}$ for the $\mathrm{V} 2 \mathrm{p}_{3 / 2}$ and $\mathrm{V} 2 \mathrm{p}_{1 / 2}$ for the $\mathrm{V}^{4+}$ and $\mathrm{V}^{5+}$ components, respectively. Both as-deposited films clearly have vanadium in the $4+$ oxidation state.

Even though the morphology and oxidation state of the asdeposited films are shown to be quite similar, a difference in film density was found by evaluating the V XRF counts, normalised to the Si-substrate XRF counts to account for surface and distance factors. When these values are compared to the film thicknesses measured by XRR, it is clear from Fig. 3 that there is more vanadium per unit thickness in the $\mathrm{H}_{2} \mathrm{O}$-deposited films than in the $\mathrm{O}_{3}$-deposited film, a direct proof that the films grown by utilizing the water process are denser when compared to those grown from the ozone process, as is consistent with XRR and XRF measurements performed in earlier work.

\section{2 $\mathrm{VO}_{x}$ crystallisation and oxidation state control for $2 \leq x$ $\leq 2.5$}

The as-deposited films using the TEMAV ALD processes are found to be amorphous by XRD with vanadium in a 4+ oxidation state. By post-ALD annealing in ambients with carefully controlled oxygen partial pressures, vanadium oxides in the $\mathrm{V}_{n} \mathrm{O}_{2 n+1}$ series could be reached. The crystallisation was
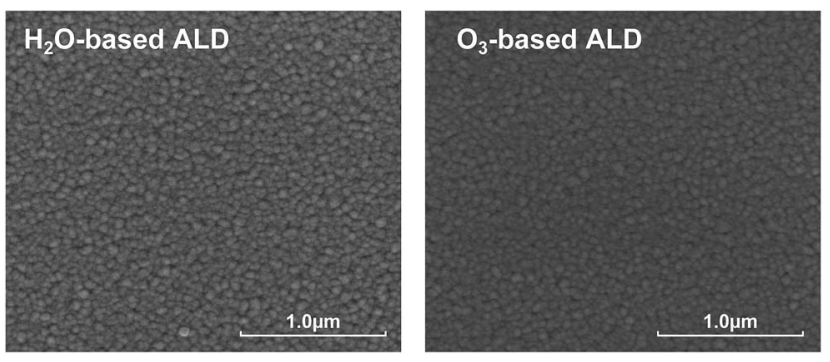

Fig. 1 Morphology of the as-deposited $\mathrm{VO}_{x}$ films on the Pt substrate as measured by SEM, showing the $\mathrm{H}_{2} \mathrm{O}$-based (left) and $\mathrm{O}_{3}$-based (right) ALD films. 


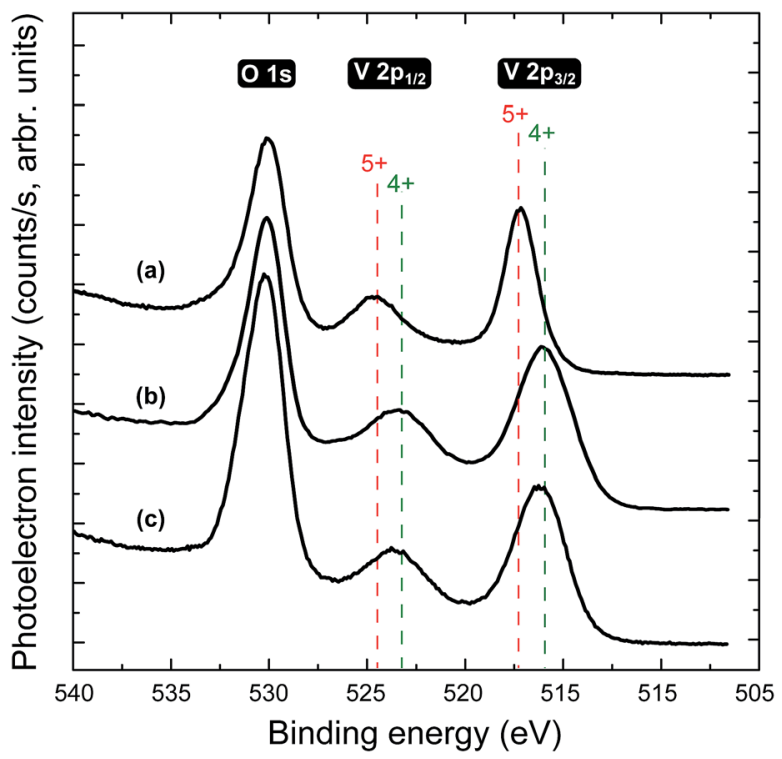

Fig. 2 XPS spectra for the $\mathrm{VO}_{x}$ film surface: (a) a crystalline $\mathrm{V}_{2} \mathrm{O}_{5}$ reference film, (b) as-deposited film using the water-based ALD process and (c) as-deposited film using the ozone-based ALD process. The binding energies are referenced to $\mathrm{O}$ 1s calibrated at $530.0 \mathrm{eV}{ }^{41}$

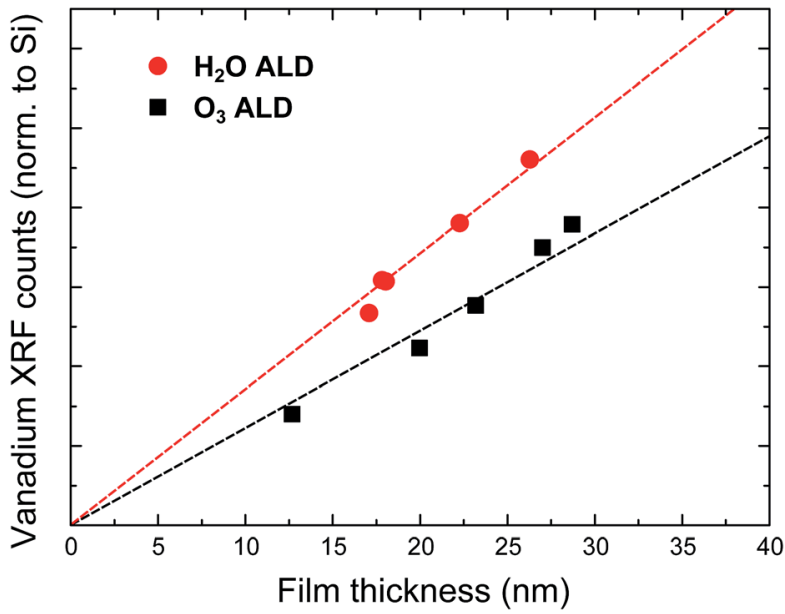

Fig. 3 Relation between the XRF vanadium counts (normalised to the $\mathrm{Si}$ signal) and the measured film thickness (XRR) for different film thicknesses for both processes. The higher values for the $\mathrm{H}_{2} \mathrm{O}$-based ALD films indicate a higher $\mathrm{VO}_{x}$ density for these films. The dashed lines are a guide to the eye to illustrate this.

monitored using in situ XRD and the oxidation states were in accordance to the crystal state, as was confirmed by XPS on selected quenches (not shown here). Ex situ XRD on selected quenches confirmed the crystal states at intermediate temperatures. The crystallisation of the thin films was investigated on three substrates: $\mathrm{SiO}_{2}$, Pt and TiN.

First, we will discuss the results on the $\mathrm{SiO}_{2}$ substrate. The

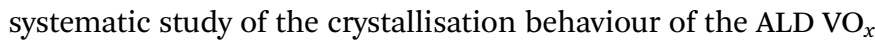
on the $\mathrm{SiO}_{2}$ substrate is presented in Fig. 4(a) and (b) for the $\mathrm{H}_{2} \mathrm{O}-$ and $\mathrm{O}_{3}$-ALD deposited films, respectively. As an example, the phase evolution of the ozone-grown film during annealing in (a) $\mathrm{H}_{2} \mathrm{O}$ ALD
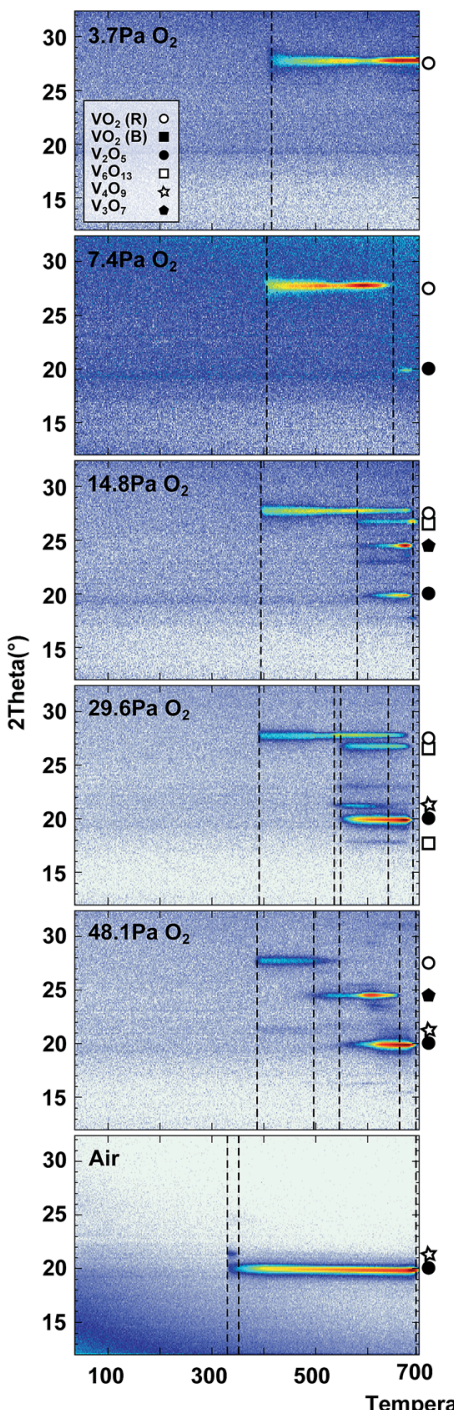

Temperature $\left({ }^{\circ} \mathrm{C}\right)$ (b) $\mathrm{O}_{3}$ ALD
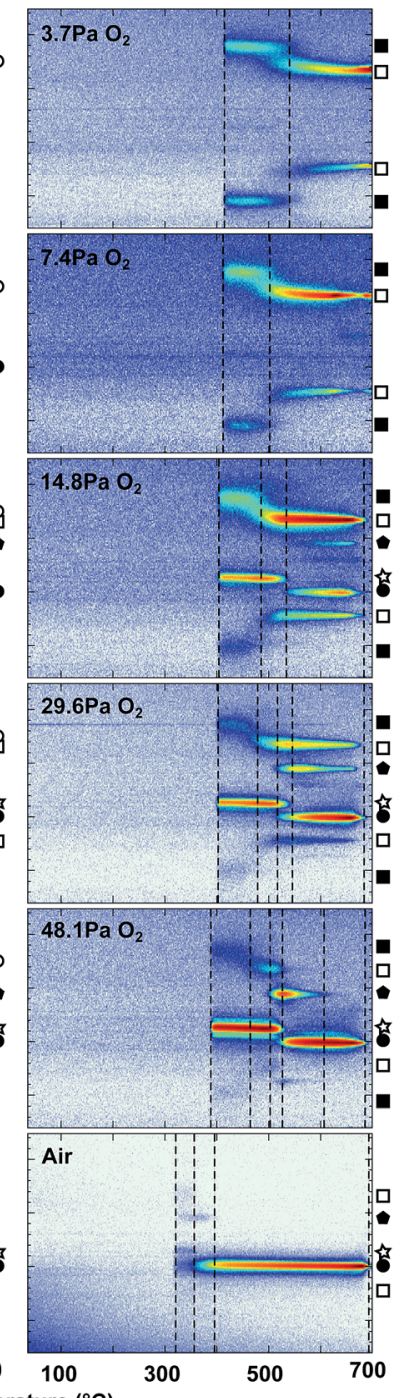

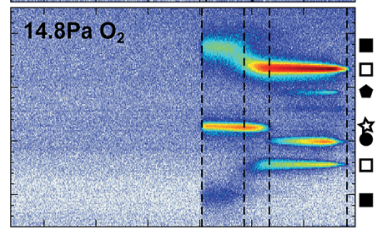

Fig. 4 Crystallisation of the as-deposited $\mathrm{VO}_{x}$ thin films on the $\mathrm{SiO}_{2}$ substrate, as studied by in situ XRD in varying oxygen partial pressure at a heating rate of $0.25^{\circ} \mathrm{C} \mathrm{s}^{-1}$. Symbols indicate $\mathrm{VO}_{x}$ crystal states $(2 \leq x$ $\leq 2.5$ ), as shown in the legend (top left).

a 3.7 Pa oxygen partial pressure is discussed here (top section of Fig. 4(b)). One can observe that the film is initially amorphous by the lack of diffraction peaks. When heating in a controlled ambient, the film crystallises into $\mathrm{VO}_{2}$ (B) just above $400{ }^{\circ} \mathrm{C}$, and finally oxidizes between 500 and $600{ }^{\circ} \mathrm{C}$ to $\mathrm{V}_{6} \mathrm{O}_{13}$.

The results of the in situ XRD measurements are summarized in 'phase formation diagrams', as shown in Fig. 5 for the crystallisation and oxidation on a $\mathrm{SiO}_{2}$ substrate. These should not be interpreted as thermodynamic phase diagrams, since no constant-temperature steps were made to allow film stabilisation to the equilibrium state, but as phase formation diagrams displaying the kinetic path the films go through while being heated at $0.25{ }^{\circ} \mathrm{C} \mathrm{s}^{-1}$ in the ambients under study (He with oxygen partial pressure of 3.7, 7.4, 14.8, 29.6 and $48.1 \mathrm{~Pa}$, and ambient air). 


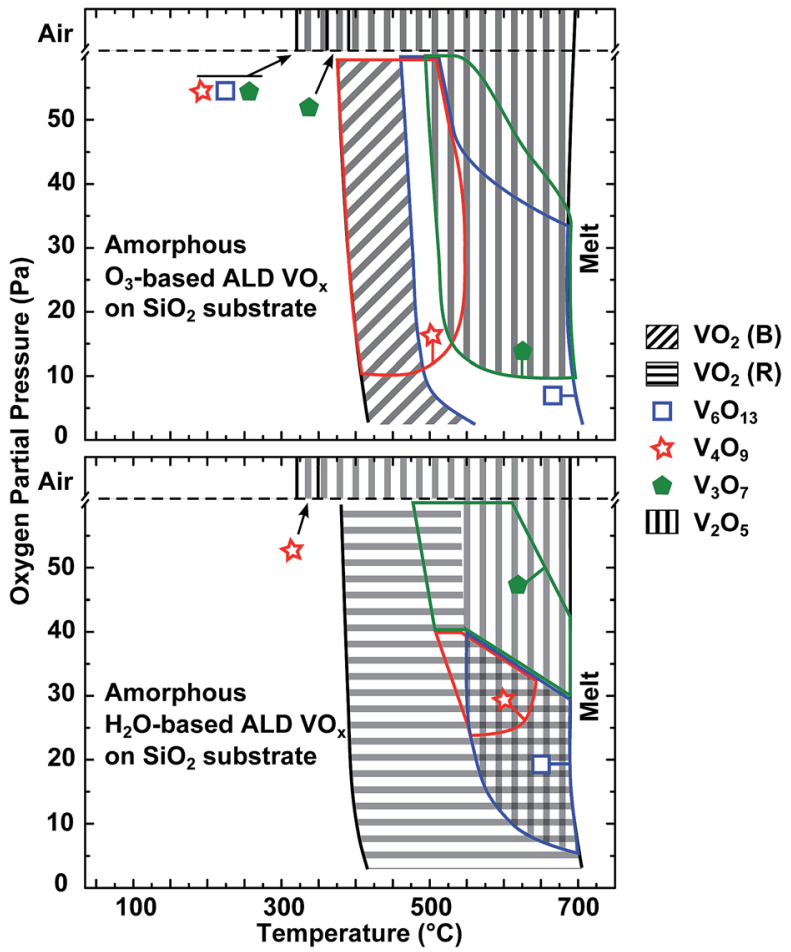

Fig. 5 Phase formation diagrams for the formation of crystalline $\mathrm{VO}_{x}$ phases ( $2 \leq x \leq 2.5$ ), based on the in situ XRD measurements (Fig. 4) at $0.25^{\circ} \mathrm{C} \mathrm{s}^{-1}$ for $\mathrm{He}$ ambients with oxygen partial pressures of 3.7, 7.4, 14.8, 29.6 and $48.1 \mathrm{~Pa}$, and in ambient air. The same set of symbols is used as in Fig. 4 except for the extrema, namely $\mathrm{VO}_{2}$ and $\mathrm{V}_{2} \mathrm{O}_{5}$ states, since these dominate the phase formation diagrams to a large extent.

The in situ XRD data provides a wealth of information on the often quite complex phase formation sequence. On $\mathrm{SiO}_{2}$ substrates, phase-pure regions were only observed for the $\mathrm{VO}_{2}$, $\mathrm{V}_{6} \mathrm{O}_{13}$ and $\mathrm{V}_{2} \mathrm{O}_{5}$ phases. A clear trend emerges when examining the influence of the oxygen partial pressure. When going through both formation diagrams in Fig. 5 from low to high oxygen partial pressure, we see that phases emerge and disappear in the order of increasing oxidation state: $\mathrm{VO}_{2}-\mathrm{V}_{6} \mathrm{O}_{13}$ $\mathrm{V}_{4} \mathrm{O}_{9}-\mathrm{V}_{3} \mathrm{O}_{7}-\mathrm{V}_{2} \mathrm{O}_{5}$ with respective average oxidation states for the $\mathrm{V}$ of 4-4.33-4.5-4.67-5. The influence of the temperature is more complex since the phases have no time to settle to an equilibrium state at each temperature, so thin-film kinetics will complicate this behaviour. However, we can see that in general with increasing temperature the average oxidation state rises to higher values, showing high-temperature stability for the higher oxides.

Furthermore, we can see the remarkable influence of the asdeposited film on the initial crystallisation of the amorphous layers. Since all parameters are equal except for the ALD process gas during the ALD process (ozone or water), this translates to an influence of the latter on the initial crystallisation. The ozone-based ALD crystallizes into the $\mathrm{VO}_{2}$ (B)-phase, while that via the water-based process crystallizes into the hightemperature stable $\left(>68{ }^{\circ} \mathrm{C}\right) \mathrm{VO}_{2}(\mathrm{R})$-state (which settles to the $\mathrm{VO}_{2}$ (M1) state when quenched in that phase). Both these phases are based on a bcc lattice with vanadium on the octahedral sites. The difference lies in the mutual orientation of the fourfold axis of the oxygen octahedra, being aligned or perpendicular for the $\mathrm{VO}_{2}(\mathrm{~B})$ and $\mathrm{VO}_{2}(\mathrm{R})$, respectively. ${ }^{43}$ This translates into a difference in structure as well as in density: $\mathrm{VO}_{2}$ (R) has a higher density $\left(4.67 \mathrm{~g} \mathrm{~cm}^{-3}\right)$ than $\mathrm{VO}_{2}$ (B) (4.03 $\mathrm{g}$ $\left.\mathrm{cm}^{-3}\right) \cdot{ }^{44}$ Earlier, we showed that the water-based process leads to growth of a higher density amorphous $\mathrm{VO}_{x}$ layer than the ozone process. The high density amorphous layer deposited using the $\mathrm{H}_{2} \mathrm{O}$-based ALD process crystallizes into the high density $\mathrm{VO}_{2}(\mathrm{R})$ phase, while the lower density amorphous layer deposited using the ozone process crystallizes initially into the lower density $\mathrm{VO}_{2}$ (B) phase. So, by choice of ALD process, we can choose to crystallise the film in either the $\mathrm{VO}_{2}$ (B) or $\mathrm{VO}_{2}$ (M1) phase for electrochemical testing.

We hypothesize that the use of ozone in the ALD process also has an influence on the oxidation behaviour. Even though XPS shows that these films have the same oxidation state for the vanadium $(4+)$, we observe a lower temperature for the introduction of higher oxidation state vanadium oxides for the ozone grown films. For the lowest oxygen partial pressure we obtain phase-pure $\mathrm{VO}_{2}$ for both films. For higher oxygen partial pressures, we see the presence of $\mathrm{V}_{4} \mathrm{O}_{9}$ upon crystallisation of the ozone grown films, having a higher oxidation state. For the water-grown films this was not the case, and we obtained phasepure $\mathrm{VO}_{2}$ for all oxygen partial pressures examined (except for air), before further oxidation occurred. Even though the oxidation state is the same, a stronger oxidant is used during the ozone-based ALD process, which could incorporate more oxygen into the films. Another hypothesis is based on the fact that the films are less dense when using the ozone process. This could allow faster oxygen diffusion into these films, enhancing the oxidation kinetics during post-ALD annealing.

The crystallisation of the films on the Pt and TiN substrates was examined next, since a current collector is required to test the vanadium oxides as LIB electrode materials. The results are shown in Fig. 6. Similar trends were observed, with again formation of the $\mathrm{VO}_{2}$ (B) or $\mathrm{VO}_{2}$ (M1) as first phases for the ozone and water-based ALD, respectively, and the $\mathrm{V}_{2} \mathrm{O}_{5}$ phase occurring at high-temperature and/or high oxygen ambients. However, one can note two main differences when comparing these phase formation diagrams to those on $\mathrm{SiO}_{2}$. Firstly, the $\mathrm{SiO}_{2}$ formation diagrams are much richer in phase zones than their counterparts on $\mathrm{Pt}$ and TiN. Furthermore, we observed that on $\mathrm{SiO}_{2}$ the transformation to higher oxidation state vanadium oxides occurs at lower temperatures than on the other investigated substrates. In the case of a TiN substrate, the vanadium oxide phases with the highest oxidation states appear at the highest temperatures, or not at all, when compared to $\mathrm{SiO}_{2}$ and Pt. The Pt case lies in between both other cases. Here, we see the influence of the TiN in the substrate. We hypothesise that the TiN-substrate acts as an oxygen drain, extracting oxygen from the film, and thus preventing further oxidation of the vanadium oxides, as was also observed by the presence of $\mathrm{TiO}_{2}$ rutile diffraction peaks in the XRD scans taken after the oxidation experiments. The $\mathrm{SiO}_{2}$ is completely oxidized already, so it does not act as an oxygen drain, lowering the oxygen pressure and temperatures required to oxidise the vanadium 
(a) TiN substrate
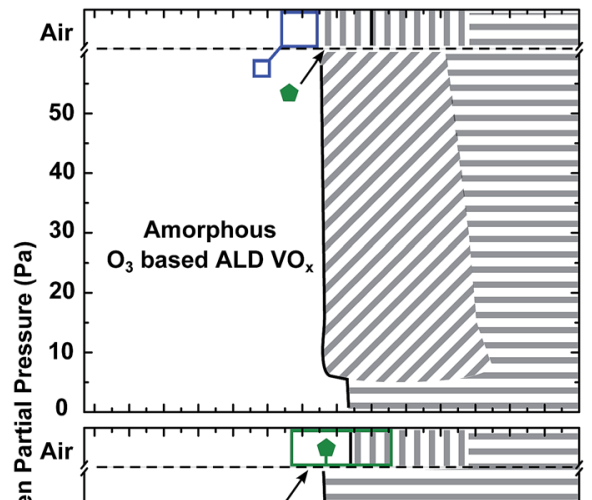

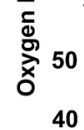

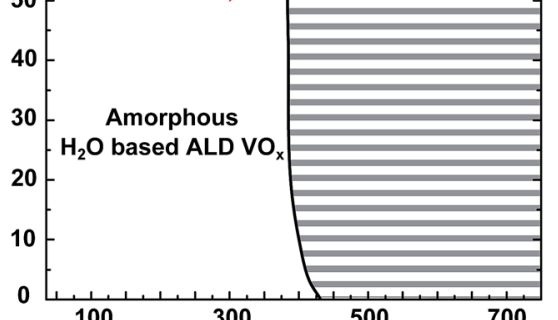

(b) Pt substrate
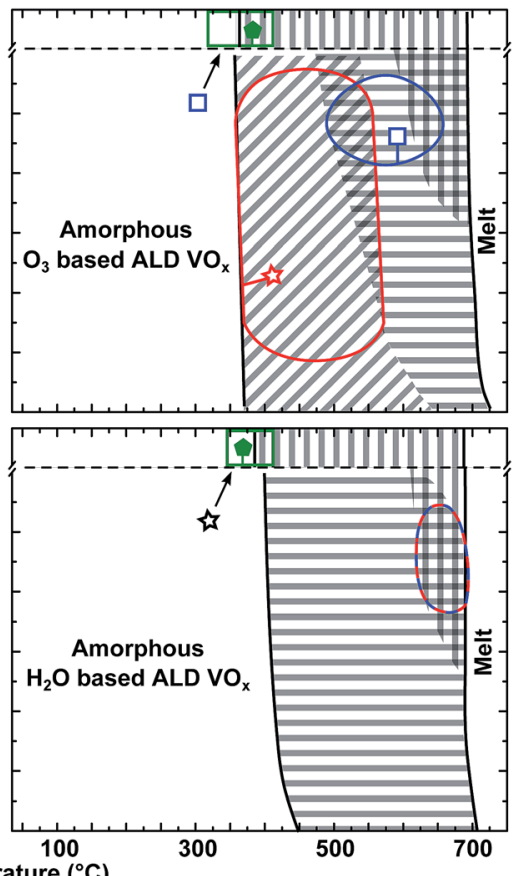

UA $\mathrm{VO}_{2}(\mathrm{~B})$

目 $\mathrm{VO}_{2}(\mathrm{R})$

$\square \mathbf{V}_{6} \mathbf{O}_{13}$

$\mathrm{V}_{4} \mathrm{O}_{9}$

- $\mathrm{V}_{3} \mathrm{O}_{7}$

III $\mathrm{V}_{2} \mathrm{O}_{5}$

Fig. 6 Phase formation diagrams for the formation of the $\mathrm{VO}_{x}$ crystal states $(2 \leq x \leq 2.5)$ on TiN substrates (left) and on Pt substrates (right), at $0.25^{\circ} \mathrm{C} \mathrm{s}^{-1}$ for He ambients with oxygen partial pressure of 3.7, 7.4, 14.8, 29.6 and 48.1 Pa, and in ambient air. The absence of the melt-line on the left figure is related to the presence of rutile $\mathrm{TiO}_{2}$ from the substrate, complicating the analysis of the $\mathrm{VO}_{2}(\mathrm{R})$ phase on the TiN substrate at high temperatures.

Table 1 Conversion paths from the as-deposited films to their crystallised and oxidized forms on the Pt-substrate

\begin{tabular}{llll}
\hline Phase & ALD reactant & Ambient & $\begin{array}{l}\text { Temperature } \\
\left({ }^{\circ} \mathrm{C}\right)\end{array}$ \\
\hline $\mathrm{VO}_{2}(\mathrm{~B})$ & $\mathrm{O}_{3}$ & $\mathrm{He}+3.7 \mathrm{~Pa} \mathrm{O}_{2}$ & 420 \\
$\mathrm{VO}_{2}(\mathrm{M} 1)$ & $\mathrm{H}_{2} \mathrm{O}$ & $\mathrm{He}+18 \mathrm{~Pa} \mathrm{O}_{2}$ & 450 \\
$\mathrm{~V}_{6} \mathrm{O}_{13}$ & $\mathrm{O}_{3}$ & $\mathrm{He}+3.7 \mathrm{~Pa} \mathrm{O}_{2}$ & 550 \\
$\mathrm{~V}_{4} \mathrm{O}_{9}$ & $\mathrm{H}_{2} \mathrm{O}$ & Ambient air & 356 \\
$\mathrm{~V}_{3} \mathrm{O}_{7}$ & $\mathrm{O}_{3}$ & $\mathrm{He}+48 \mathrm{~Pa} \mathrm{O}_{2}$ & 560 \\
$\mathrm{~V}_{2} \mathrm{O}_{5}$ & $\mathrm{H}_{2} \mathrm{O}$ or $\mathrm{O}_{3}$ & Ambient air & 500
\end{tabular}

oxides. The Pt substrate has a TiN layer underneath. Since oxygen can diffuse through the Pt layer, the underlying TiN can still get oxidized, as was confirmed by XRD. However, this oxidation is delayed by the presence of the Pt layer. This causes both observed differences: the phase-richness in the formation diagrams likely also occurs for TiN or Pt substrates, but at higher oxygen partial pressures than examined here, when the supply of oxygen is higher than the harvesting effect of the TiN.

\subsection{Electrochemical characterisation of the possible $\mathrm{VO}_{x}$ phases $(2 \leq x \leq 2.5)$}

All of the obtained crystalline vanadium oxides $\left(\mathrm{VO}_{2}(\mathrm{~B}), \mathrm{VO}_{2}\right.$ (M1), $\mathrm{V}_{6} \mathrm{O}_{13}, \mathrm{~V}_{4} \mathrm{O}_{9}, \mathrm{~V}_{3} \mathrm{O}_{7}$ and $\mathrm{V}_{2} \mathrm{O}_{5}$ ) were tested as LIB electrodes on Pt substrates. Film crystallisation was monitored by in situ $\mathrm{XRD}$ to ensure corresponding phase formations and

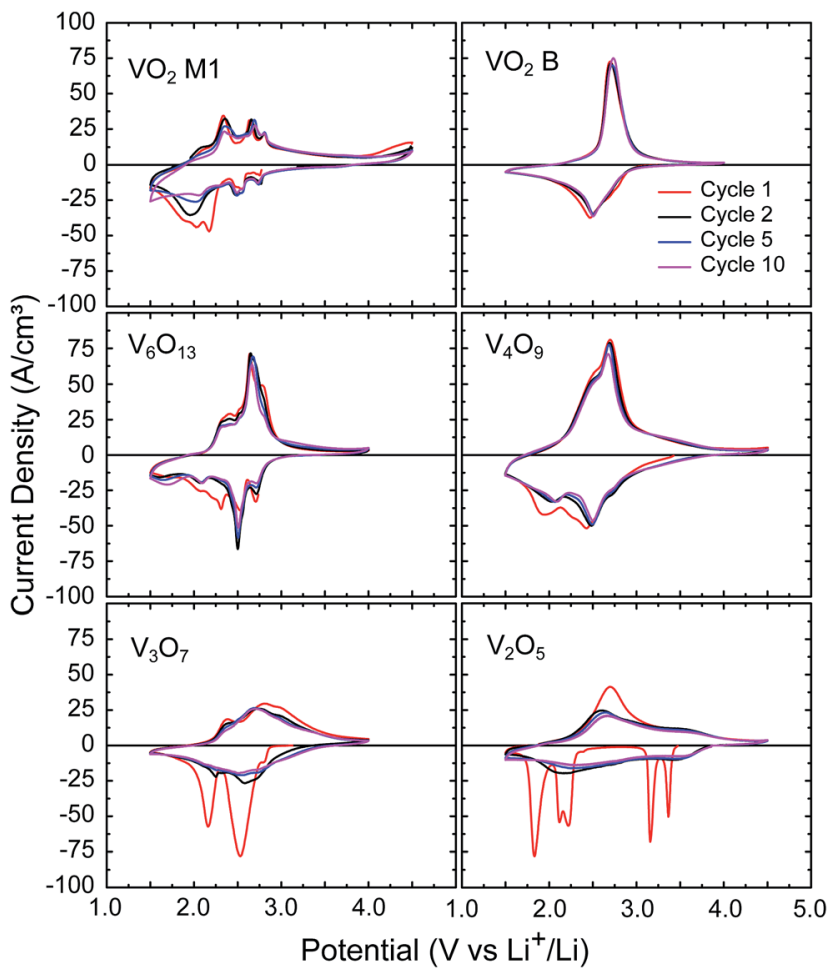

Fig. 7 Cyclic voltammetry on the selected vanadium oxide thin films, performed at $10 \mathrm{mV} \mathrm{s}^{-1}$ in a three-electrode setup with lithium as counter and reference electrodes, and $1 \mathrm{M} \mathrm{LiClO}_{4}$ in $\mathrm{PC}$ as electrolyte. Potential ranges were chosen according to activity. 


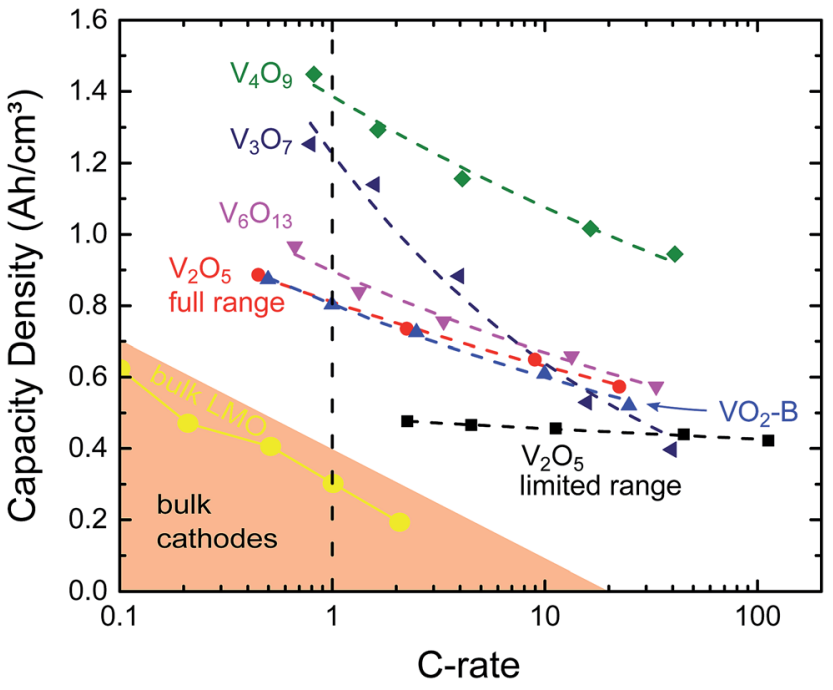

Fig. 8 Measured delithiation capacity of the examined films on a logarithmic-linear scale (solid symbols). The data was extrapolated (dashed lines) resulting in a good match to the data $\left(R^{2}>0.98\right)$. Micron-sized LMO is shown as a model bulk cathode, (red circles) ${ }^{46}$ and more general bulk cathodes (shaded left corner) ${ }^{45}$ from literature are shown for comparison.

Table 2 Delithiation capacities for the examined thin films, calculated by charging and discharging the films at varying current density over several orders of magnitude and extrapolating the measured capacity to $1 \mathrm{C}$ (Fig. 8), which corresponds to the current necessary to reach the theoretical capacity in 1 hour. Volumetric capacities of commercial cathode materials are included for comparison ${ }^{45}$

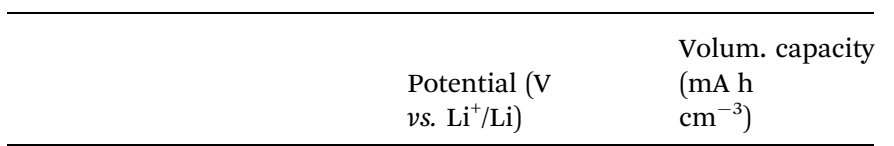

$\begin{array}{lll}\text { This work } & & \\ \mathrm{VO}_{2}(\mathrm{M} 1) & 1.5-4.0 & \text { No activity } \\ \mathrm{VO}_{2}(\mathrm{~B}) & 1.5-4.0 & 805(1 \mathrm{C}) \\ \mathrm{V}_{6} \mathrm{O}_{13} & 1.5-4.0 & 894(1 \mathrm{C}) \\ \mathrm{V}_{4} \mathrm{O}_{9} & 1.5-4.0 & 1380(1 \mathrm{C}) \\ \mathrm{V}_{3} \mathrm{O}_{7} & 1.5-4.0 & 1255(1 \mathrm{C}) \\ \mathrm{V}_{2} \mathrm{O}_{5}\left(\rightarrow \mathrm{LiV}_{2} \mathrm{O}_{5}\right) & 2.9-3.5 & 488(1 \mathrm{C}) \\ \mathrm{V}_{2} \mathrm{O}_{5}\left(\rightarrow \mathrm{Li}_{3} \mathrm{~V}_{2} \mathrm{O}_{5}\right) & 1.5-4.0 & 810(1 \mathrm{C})\end{array}$

Commercial cathode materials

$\begin{array}{lll}\mathrm{LiCoO}_{2} & 3.8 & 550 \\ \mathrm{LiMn}_{2} \mathrm{O}_{4} & 4.1 & 596 \\ \mathrm{LiFePO}_{4} & 3.4 & 589 \\ \mathrm{LiNi}_{0.33} \mathrm{Mn}_{0.33} \mathrm{Co}_{0.33} \mathrm{O}_{2} & 3.7 & 600 \\ \mathrm{LiNi}_{0.8} \mathrm{Co}_{0.15} \mathrm{Al}_{0.05} \mathrm{O}_{2} & 3.8 & 700\end{array}$

oxidations, $\dagger$ and results are summarised in Table 1 . Only $\mathrm{V}_{3} \mathrm{O}_{7}$ was not obtainable in a phase-pure form on the Pt substrate, but the oxidation path indicated in Table 1 shows only a small fraction of the $\mathrm{V}_{3} \mathrm{O}_{7}$ film crystallised to $\mathrm{V}_{2} \mathrm{O}_{5}$, as was confirmed by XRD and XPS. This makes the $\mathrm{V}_{3} \mathrm{O}_{7}$ almost phase-pure, and will be denoted further simply as $\mathrm{V}_{3} \mathrm{O}_{7}$. The path to $\mathrm{V}_{6} \mathrm{O}_{13}$ does not match the phase formation diagram, since phase-pure $\mathrm{V}_{6} \mathrm{O}_{13}$ was obtained by performing a ramp slower than the one used for the formation diagrams. Cyclic voltammetry at $10 \mathrm{mV} \mathrm{s}^{-1}$ was performed down to $1.5 \mathrm{Vvs} . \mathrm{Li}^{+} / \mathrm{Li}$ to examine the electrochemical intercalation behaviour of the different vanadium oxides. As can be seen in Fig. 7, all phases show a clear lithiation and delithiation behaviour. However, even though the $\mathrm{VO}_{2}$ (M1) appeared to show activity, initial galvanostatic chargedischarge tests showed only very low electrochemical storage capacity. Furthermore, some peaks of the cyclic voltammogram appear closely related to the electrochemical activity of the Pt substrate, as shown in ESI. $\dagger$ Due to the absence of storage of lithium into these films, $\mathrm{VO}_{2}$ (M1) was not examined in-depth further. All other films showed a clear lithium insertion/ extraction behaviour, indicating lithium can be stored in these films reversibly.

Galvanostatic charging and discharging was performed on the films to determine the available storage capacity and compare it to $\mathrm{V}_{2} \mathrm{O}_{5}$, which is the most investigated form of vanadium oxide and is generally considered to be the most promising phase. The films were cycled at varying current densities between $0.1 \mathrm{C}$ and $100 \mathrm{C}$, and the capacity was extrapolated to the $1 \mathrm{C}$ capacity to allow direct comparison between the different $\mathrm{VO}_{x}$ phases, as shown in Fig. 8. Extrapolation was performed by fitting a linear relation to the logarithm of the capacity plotted to the logarithm of the C-rate, which provided fits with $R^{2}>0.98$, demonstrating the validity of this approach. Table 2 summarizes the extrapolated capacities at 1C. Both Table 2 and Fig. 8 clearly demonstrate that, although $\mathrm{V}_{2} \mathrm{O}_{5}$ is the most investigated vanadium oxide for LIB cathodes, the capacity of the stable region (which corresponds to insertion of one lithium into $\mathrm{V}_{2} \mathrm{O}_{5}$ ), has a limited volumetric capacity. This is related to the low density of this $\mathrm{V}_{2} \mathrm{O}_{5}\left(3.36 \mathrm{~g} \mathrm{~cm}^{-3}\right)$ compared to that of commercial lithium-ion cathodes such as $\mathrm{LiCoO}_{2}$ $\left(4.9 \mathrm{~g} \mathrm{~cm}^{-3}\right) .{ }^{45}$ All of the other investigated vanadium oxide phases have capacities well above the commercial cathodes, which is spearheaded by $\mathrm{LiNi}_{0.33} \mathrm{Mn}_{0.33} \mathrm{Co}_{0.33} \mathrm{O}_{2}$ (NMC) with a capacity of $600 \mathrm{~mA} \mathrm{~h} \mathrm{~cm}^{-3}$. The higher capacity for other vanadium oxides has an origin in increased material density and insertion range. First, the densities of the lower oxidation state vanadium oxides are higher than that of $\mathrm{V}_{2} \mathrm{O}_{5}$, leading to a higher volumetric capacity density; $\mathrm{V}_{3} \mathrm{O}_{7}, \mathrm{~V}_{4} \mathrm{O}_{9}, \mathrm{~V}_{6} \mathrm{O}_{13}$ and the $\mathrm{VO}_{2}$ (B) films have densities of 3.61, 3.78, 3.91 and $4.0 \mathrm{~g} \mathrm{~cm}^{-3}$, respectively. Second, while $\mathrm{V}_{2} \mathrm{O}_{5}$ can only be used in the narrow range that leads to $\mathrm{LiV}_{2} \mathrm{O}_{5}$, i.e. reduction of vanadium from $\mathrm{V}^{5+}$ to an average oxidation state of $\mathrm{V}^{4.5+}$, the vanadium in the series of vanadium oxides tested here changes its oxidation state much more, ranging from a change in average oxidation state of 0.62 for $\mathrm{VO}_{2}$ (B) to almost 1.2 for $\mathrm{V}_{4} \mathrm{O}_{9}$. So, while $\mathrm{V}_{2} \mathrm{O}_{5}$ and $\mathrm{VO}_{2}$ (B) are generally considered the most promising cathode materials, vanadium oxides in between them exhibit higher volumetric capacities.

\section{Conclusions}

We demonstrated the deposition of two different forms of amorphous $\mathrm{VO}_{2}$ using two different ALD chemistries based on the same TEMAV precursor. Films were shown to be similar in morphology and as-deposited oxidation state of vanadium, but 
differ in density. By annealing these films in controlled ambients with varying oxygen partial pressures, we demonstrated that all crystalline phases between $\mathrm{VO}_{2}$ and $\mathrm{V}_{2} \mathrm{O}_{5}$ could be obtained. The substrate was found to influence the oxidation and crystallisation behaviour, with TiN acting as an oxygen drain delaying the oxidation. All obtained crystalline phases were characterised electrochemically, and showed activity as lithiumion electrodes. We demonstrated that, while $\mathrm{V}_{2} \mathrm{O}_{5}$ is the most widely investigated vanadium-based cathode material, also $\mathrm{VO}_{2}$ (B), $\mathrm{V}_{6} \mathrm{O}_{13}, \mathrm{~V}_{4} \mathrm{O}_{9}$ and $\mathrm{V}_{3} \mathrm{O}_{7}$ can be used as cathodes, with capacities up to $1380 \mathrm{~mA} \mathrm{~h} \mathrm{~cm} \mathrm{~cm}^{-3}\left(\mathrm{~V}_{4} \mathrm{O}_{9}\right)$, more than twice the volumetric capacity for commercial cathode materials such as NMC.

\section{Acknowledgements}

The authors acknowledge the IWT-Vlaanderen, BOF-UGent (GOA 01G01513), M-ERA LaminaLion, SBO SoS-Lion and the Hercules foundation for financial support. The authors also thank N. Deroo and Dr Ir. K. Devloo-Casier for the XPS measurements, and O. Janssens for assistance with the SEM and EDX measurements. J. D. and T. D. acknowledge the Flemish FWO for a postdoctoral and aspirant fellowship, respectively. Finally, the authors would like to thank the Air Liquide Advanced Materials team to provide us with the TEMAV precursor.

\section{References}

1 D. Miorandi, S. Sicari, F. De Pellegrini and I. Chlamtac, Ad Hoc Networks, 2012, 10, 1497-1516.

2 H. Sundmaeker, P. Guillemin, P. Friess and S. Woelfflé, European Commission and Directorate-General for the Information Society and Media, Vision and challenges for realising the Internet of things, EUR-OP, Luxembourg, 2010.

3 A. S. M. Zahid Kausar, A. W. Reza, M. U. Saleh and H. Ramiah, Renewable Sustainable Energy Rev., 2014, 38, 973-989.

4 M. Létiche, E. Eustache, J. Freixas, A. Demortière, V. De Andrade, L. Morgenroth, P. Tilmant, F. Vaurette, D. Troadec, P. Roussel, T. Brousse and C. Lethien, Adv. Energy Mater., 2016, 1601402.

5 Y. Wang, W. D. Richards, S. P. Ong, L. J. Miara, J. C. Kim, Y. Mo and G. Ceder, Nat. Mater., 2015, 14, 1026-1031.

6 J. Keränen, A. Auroux, S. Ek and L. Niinistö, Appl. Catal., A, 2002, 228, 213-225.

7 G. Rampelberg, M. Schaekers, K. Martens, Q. Xie, D. Deduytsche, B. De Schutter, N. Blasco, J. Kittl and C. Detavernier, Appl. Phys. Lett., 2011, 98, 162902.

8 M. S. Whittingham, J. Electrochem. Soc., 1976, 123, 315-320. 9 D. W. Murphy, P. A. Christian, F. J. DiSalvo and J. V. Waszczak, Inorg. Chem., 1979, 18, 2800-2803.

10 P. G. Dickens, S. J. French, A. T. Hight and M. F. Pye, Mater. Res. Bull., 1979, 14, 1295-1299.

11 C. Delmas, H. Cognac-Auradou, J. M. Cocciantelli, M. Ménétrier and J. P. Doumerc, Solid State Ionics, 1994, 69, 257-264.
12 Y. Liu, M. Clark, Q. Zhang, D. Yu, D. Liu, J. Liu and G. Cao, Adv. Energy Mater., 2011, 1, 194-202.

13 C. Leger, S. Bach, P. Soudan and J.-P. Pereira-Ramos, J. Electrochem. Soc., 2005, 152, 236-241.

14 Y. S. Cohen and D. Aurbach, Electrochem. Commun., 2004, 6, 536-542.

15 A. Pan, H. B. Wu, L. Yu, T. Zhu and X. W. D. Lou, ACS Appl. Mater. Interfaces, 2012, 4, 3874-3879.

16 S.-L. Chou, J.-Z. Wang, J.-Z. Sun, D. Wexler, M. Forsyth, H.-K. Liu, D. R. MacFarlane and S.-X. Dou, Chem. Mater., 2008, 20, 7044-7051.

17 N. Ganganagappa and A. Siddaramanna, Mater. Charact., 2012, 68, 58-62.

18 H. A. Wriedt, Bull. Alloy Phase Diagrams, 1989, 10, 271-277. 19 M. S. Whittingham, Chem. Rev., 2004, 104, 4271-4302.

20 D. W. Murphy, P. A. Christian, F. J. DiSalvo and J. V. Waszczak, Inorg. Chem., 1979, 18, 2800-2803.

21 X. Huang, X. Rui, H. H. Hng and Q. Yan, Part. Part. Syst. Charact., 2015, 32, 276-294.

22 J. Jiang, Y. Li, J. Liu, X. Huang, C. Yuan and X. W. D. Lou, Adv. Mater., 2012, 24, 5166-5180.

23 J. F. M. Oudenhoven, L. Baggetto and P. H. L. Notten, Adv. Energy Mater., 2011, 1, 10-33.

24 Y. Wang and G. Cao, Adv. Mater., 2008, 20, 2251-2269.

25 L. Baggetto, R. A. H. Niessen, F. Roozeboom and P. H. L. Notten, Adv. Funct. Mater., 2008, 18, 1057-1066.

26 J. W. Long, B. Dunn, D. R. Rolison and H. S. White, Chem. Rev., 2004, 104, 4463-4492.

27 X. Meng, X.-Q. Yang and X. Sun, Adv. Mater., 2012, 24, 35893615.

28 J. Musil, P. Baroch, J. Vlček, K. Nam and J. Han, Thin Solid Films, 2005, 475, 208-218.

29 T. J. Hanlon, R. E. Walker, J. A. Coath and M. A. Richardson, Thin Solid Films, 2002, 405, 234-237.

30 N. Bahlawane and D. Lenoble, Chem. Vap. Deposition, 2014, 20, 299-311.

31 J. Dendooven, D. Deduytsche, J. Musschoot, R. L. Vanmeirhaeghe and C. Detavernier, J. Electrochem. Soc., 2010, 157, G111-G116.

32 J. C. Badot, S. Ribes, E. B. Yousfi, V. Vivier, J. P. PereiraRamos, N. Baffier and D. Lincot, Electrochem. Solid-State Lett., 2000, 3, 485-488.

33 P. Dagur, A. U. Mane and S. Shivashankar, J. Cryst. Growth, 2005, 275, 1223-1228.

34 P. A. Premkumar, M. Toeller, I. P. Radu, C. Adelmann, M. Schaekers, J. Meersschaut, T. Conard and S. V. Elshocht, ECS J. Solid State Sci. Technol., 2012, 1, P169-P174.

35 T. Blanquart, J. Niinistö, M. Gavagnin, V. Longo, M. Heikkilä, E. Puukilainen, V. R. Pallem, C. Dussarrat, M. Ritala and M. Leskelä, $R S C A d v$., 2012, 3, 1179-1185.

36 G. Rampelberg, D. Deduytsche, B. De Schutter, P. A. Premkumar, M. Toeller, M. Schaekers, K. Martens, I. Radu and C. Detavernier, Thin Solid Films, 2014, 550, 5964.

37 M.-G. Willinger, G. Neri, E. Rauwel, A. Bonavita, G. Micali and N. Pinna, Nano Lett., 2008, 8, 4201-4204. 
38 J. Musschoot, Q. Xie, D. Deduytsche, S. Van den Berghe, R. L. Van Meirhaeghe and C. Detavernier, Microelectron. Eng., 2009, 86, 72-77.

39 Q. Xie, Y.-L. Jiang, C. Detavernier, D. Deduytsche, R. L. V. Meirhaeghe, G.-P. Ru, B.-Z. Li and X.-P. Qu, J. Appl. Phys., 2007, 102, 083521.

40 A. P. Peter, K. Martens, G. Rampelberg, M. Toeller, J. M. Ablett, J. Meersschaut, D. Cuypers, A. Franquet, C. Detavernier, J.-P. Rueff, M. Schaekers, S. Van Elshocht, M. Jurczak, C. Adelmann and I. P. Radu, Adv. Funct. Mater., 2015, 25, 679-686.

41 J. Mendialdua, R. Casanova and Y. Barbaux, J. Electron Spectrosc. Relat. Phenom., 1995, 71, 249-261.
42 G. Silversmit, D. Depla, H. Poelman, G. B. Marin and R. De Gryse, J. Electron Spectrosc. Relat. Phenom., 2004, 135, 167175.

43 C. Leroux, G. Nihoul and G. Van Tendeloo, Phys. Rev. B: Condens. Matter Mater. Phys., 1998, 57, 5111-5121.

44 C. Leroux, G. Nihoul and G. Van Tendeloo, Phys. Rev. B: Condens. Matter Mater. Phys., 1998, 57, 5111-5121.

45 N. Nitta, F. Wu, J. T. Lee and G. Yushin, Mater. Today, 2015, 18, 252-264.

46 B. Ebin, V. Battaglia and S. Gërmen, Ceram. Int., 2014, 40, 7029-7035. 